\title{
AFROCÊNICA: POÉTICAS DE CENAS PRETAS
}

Tássio Ferreira ${ }^{1}$

Resumo: O presente trabalho reflete sobre a criação de um conceito acerca da observação de novas poéticas africanas e afrodiaspóricas da cena teatral contemporânea. Para isto, relacionamos o referido conceito a uma proposta metodológica de ensino das artes, intitulada Pedagogia da Circularidade. Esta diretriz considera a cognição de qualquer processo por uma perspectiva descolonizada, compreendendo o indivíduo integralizado no processo, como proponente direto de ações e partilhas de conhecimento, desierarquizando o saber e a produção artística. Nestas reflexões agrupamos algumas estratégias de criação, com exemplos claros, especificamente na produção de três grupos: Grupo Elinga-Teatro (1988, Luanda, Angola), Bando de Teatro Olodum (1990, Salvador, Bahia, Brasil) e NATA (1998, Alagoinhas, Bahia, Brasil). De modo que, trançaremos esta pesquisa com o conceito de campo expandido de Illena Diéguez (2014).

Palavras-chave: afroperspectiva; teatro; teatralidades; cena contemporânea; processo criativo.

\section{AFROSCENIC: BLACK SCENES POETICS}

\begin{abstract}
The present work reflects about the creation of a concept about observating new africans poetics e afrodiasporics from contemporanean theatric scenes. For this reason, we relate the referred concept to an art teaching methodological proposal, titled Circularity Pedagogy. This guideline considers any process cognition by a decolonized perspective, comprising the individual person integrated to the process as a direct proponent of actions and knowledge sharing, eliminating knowledge hierarchy and the artistic production. At these reflections we group some creation strategies, with clear examples, specifically at three different groups' productions: Grupo Elinga-Teatro (1988, Luanda, Angola), Bando de Teatro Olodum (1990, Salvador, Bahia, Brazil) and NATA (1998, Alagoinhas, Bahia, Brazil). So, we will collate this research with the "expanded field" concept of Ileana Diéguez (2014).
\end{abstract}

Keywords: afroperspective; theater; theatricality; contemporary scene; creative process.

\section{AFROSCÈNIQUE: POETIQUES DE SCENES NOIRES}

Résumé: Le présent travail reflète la création d 'un concept sur l' observation de nouvelles poétiques africaines et afro - diasporiques de la scène théâtrale contemporaine. Pour cela, nous relions le concept visé à une proposition méthodologique d'enseignement des arts, intitulée Pédagogie de la Circularité. Cette directrice considère la connaissance de tout processus par une perspective décolonisée, en considérant l'individu intégré dans le processus comme promoteur directs des actions et du partage des connaissances, en eliminand la hierarchie du savoir et la production artistique. Dans ces réflexions, nous groupons abordé quelques stratégies de création, avec des exemples clairs, en particulier dans la production de trois groupes: Grupo Elinga-Teatro (1988, Luanda, Angola), Bando de Teatro Olodum (1990, Salvador, Bahia, Brésil) e NATA (1998, Alagoinhas, Bahia, Brésil). Nous allons donc rassembler cette rechèrche avec le concept de "champ élargi" de Illena Diéguez (2014).

\footnotetext{
${ }^{1}$ Professor Assistente da Universidade Federal do Sul da Bahia (UFSB), IHAC/ Centro de Formação em Artes, Campus Jorge Amado (Itabuna-Ba). Doutorando em Artes Cênicas pelo Programa de Pósgraduação em Artes Cênicas da Universidade Federal da Bahia (PPGAC/UFBA). Taata dya Nkisi do Terreiro Unzó ia Kisimbi ria Maza Nzambi (Simões Filho-Ba). E-mail: tassio.ferreira@ yahoo.com.br
}

Revista da ABPN • v. 11, n. 27 • nov 2018 - fev 2019, p.86-112 
Mots-clés: afroperspective; thêâtre; théâtralités; scène contemporaine; processus créatif.

\section{AFROCENICA: POÉTICAS DE ESCENAS NEGRAS}

Resumen: El presente trabajo reflexiona sobre la creación de un concepto acerca de la observación de nuevas poéticas africanas y afrodiaspóricas de la escena teatral contemporánea. Para ello, relacionamos el referido concepto a una propuesta metodológica de enseñanza de las artes, titulada Pedagogía de la Circularidad. Esta directriz considera la cognición de cualquier proceso por una perspectiva descolonizada, comprendiendo al individuo integralizado en el proceso, como proponente directo de acciones y reparticiones de conocimiento, desentrelazando el saber y la producción artística. En estas reflexiones agrupamos algunas estrategias de creación, con ejemplos claros, específicamente en la producción de tres grupos: Grupo ElingaTeatro (1988, Luanda, Angola), Banda de Teatro Olodum (1990, Salvador, Bahía, Brasil) y NATA (1998, Alagoinhas, Brasil, Brasil). De modo que, encerraremos esta investigación con el concepto de campo ampliado de Ilena Diéguez (2014).

Palabras clave: afroperspectiva; teatro; teatralidad; escena contemporánea; proceso creativo.

KIUÁ, PAMBU NZILA! (VIVA O SENHOR DOS CAMINHOS!) - PARA GIRAR A GIRA

Dizem que ele viu Oxalá fazer o homem Dizem que foram dezesseis anos aprendendo Calado, sem perguntar, prestando atenção em tudo.

Esse conhece o humano desde a essência. Porque ele é o primeiro, Yangi. Ele veio antes de vir

E viu todo mundo vindo E pisando na laterita pesada.

Ficou assim, ó: olhando tudo, observando tudo. Mas, minha filha, quando este ser aprendeu tudo

E Orunmilá o transformou em dono da porta

Ele ouvia e falava tudo ao mesmo tempo

Ele ouviu o caos do mundo

E parou para organizar. Sabe com o quê? Com a boca! (Fragmento do texto Exu - A boca do universo, 2014)

(Barbosa, 2016, p.120)

No momento em que esforço-me para compreender estas epistemologias que envolvem o pensamento afrodiaspórico no trabalho com as artes cênicas na contemporaneidade, encontro-me dentro do Unzó ua Pambu Nzila (Casa do Senhor dos Caminhos, etnia Bantu, Kikoongo, Angola), do Terreiro Unzó ia Kisimbi ria Maza $\mathrm{Nzambi}^{2}$ Curiosamente, ou pela necessidade ancestral de refletir sobre meu trabalho enquanto docente/criador, estou na casa de Exu, Nkisi/Vodum/Orixá que representa o próprio movimento, a comunicação, o ir e vir, o elo, a circularidade, a comunicação entre o mundo espiritual e a vida terrena. Nzila ou Exu, arquétipo popular no imaginário

\footnotetext{
${ }^{2}$ Terreiro de matriz Congo-Angola, situado no município de Simões Filho-BA.
} 
dos baianos, a todo instante é entoado pela boca daqueles que os comparam com um ser ruim, negativo, relacionado ao sexo, orgia, conquistas amorosas, morte, feitiçaria, dentre muitas imagens possíveis, que nem sempre fazem jus a sua real atuação simbólica. Jorge Amado diz que Exu é aquele que atirou uma pedra ontem para matar um pássaro hoje. Figura contraditória por natureza, porém fundamental nos cultos afrobrasileiros para que a dinâmica religiosa aconteça. Vanda Machado (2010, p.12) traz outras qualidades que nos ajudam a compreender esta mítica representação:

Exu é o princípio, o meio e o fim. Exu está na árvore, no rio, no peixe, no pássaro, na pedra e em todo ser vivente. Como elemento energético dinamizador e plasmador, ele é o que desenvolve, mobiliza, faz crescer, transformar. É o que faz comunicar no incessante fluxo das vivências cotidianas entre o Orun e o Aiyê, o mundo espiritual e o mundo natural. Ele é o tudo e o nada. Seu jeito buliçoso de existir encontra ressonância no pensamento filosófico de um universo sem lógica. Um universo de lógicas infinitas, um universo polilógico.

Não se faz nada sem Pambu Nzila ou simplesmente Nzila. Sem o "agradá-lo" previamente, não há festa, não há candomblé, não se pode iniciar a criação de nenhuma energia dentro de uma Unzó (Casa de candomblé na nação Angola). Nzila prepara o terreiro para que os ritos aconteçam. Nzila não é diabo, satanás, demônio. Não o reconhecemos desta forma. Neste sentido, iniciar com Nzila dentro de um contexto artístico-mito-poético, considerando seus aspectos de imaginário popular - nunca religiosos - é importante para o start da desconstrução negativa daquilo que está relacionado ao povo negro: religião, músicas, cores, comidas, arte etc.

$\mathrm{Na}$ ideia de compreender possíveis práticas que contemplem os estudos acerca da cultura africana e afro-brasileira, Nzila não pode ser negligenciado, porque ele é o próprio símbolo do círculo, circularidade, do ir e retornar, de não hierarquizar, de possibilitar acesso a todxs, sobretudo no universo das artes. Como Exu não tem caminhos para caminhar, dentro da esfera dos processos de criação, o processor/encenador/criador deve estar dotado do arquétipo de Nzila, para entender compreender os modos disformes de aprendizado a partir de uma perspectiva descolonizada.

O senso-comum observa apenas um lado das coisas: é parcial. Vê apenas uma direção: é linear. Exu não é apenas branco ou vermelho. Ele é policrômico: branco, vermelho, verde, preto... Ele anda em todas as direções no mesmo instante (Oliveira, 2007, p.165). 
Não se pode ter caminhos demarcados, não se pode ter um fim preciso. Deve-se ter um início, possibilidades de provocação e muitos objetivos traçados, para que alguns deles sejam talvez atravessados. Nestas perspectivas iniciais, peço licença ao nosso mandingueiro, para que reforce a ideia do circular como possibilidades de compreender o que viria a ser nossa cena afro, ou melhor, nossa Afrocênica:

Pensamento é movimento para Exu. Ao mesmo tempo que se farta, oferece. Ao mesmo tempo que oferta, toma. Concomitantemente fortalece e enfraquece, empodera e empobrece. Exu é mandinga de ancestral em ânsia de sedução [da humanidade] (Oliveira, 2007, p.165).

Kiuá, Pambu Nzila! Pembelể ! A minha gira está aberta!

\section{PEMBELÊ, MAM'ETU MAZA (NÓS O SAUDAMOS, MÃE DAS ÁGUAS): O ENCONTRO DAS ÁGUAS ATLÂNTICAS}

Entender o que vem a ser a Afrocênica não é difícil para os olhos descolonizados, livre das amarras eurocentradas que nem consideraram negros como produtores de arte e conhecimento, de modo geral. Portanto, pensar acerca desta concepção de arte que não parte da representação conceitual, e, sim, da representação simbólico-espiritual, é uma tarefa difícil aos olhos viciados em uma única perspectiva. O convite aqui é lavar os olhos com as nossas águas ancestrais para seguir com nossa viagem. Rogo aqui a Kaiala, Kokueto, Samba, Kaitumba, Kisimbi, Ndanda Nlunda e todas as Muhatu ${ }^{4}$ do panteão Bantu, para ajudar na travessia.

A própria essência da arte negro-africana é de significar e não de imitar; é de levar a forma que aparece na matéria a apresentar uma mensagem; ela é uma arte comunicativa. A disparidade da qual fala Levis-Strauss não se deve absolutamente aos meios técnicos. Que a madeira fosse dura ou mole, a função significativa é um atributo da obra que é deliberadamente buscada. As estátuas ancestrais (salvo raras exceções) não devem, apesar da forma humana, assemelhar-se com uma pessoa determinada. Devem ser como pessoas, mas não como pessoas determinadas. A arte africana tradicional não é uma arte de imitação. É uma arte de presentificação, embora tenhamos poucos casos de representação, por exemplo, as cabeças comemorativas na arte de Ifé, Benim e arte real Kuba da República Democrática do Congo. (Munanga, 2006)

O Professor Kabengele Munanga vem tratar justamente do entendimento desta afroperspectiva, muitas vezes atropelada por outros pesquisadores, que lançam mão de

\footnotetext{
${ }^{3}$ Kiuá, Nzila! Pembelê - do bantu, na língua Kikoongo quer dizer: "Viva, Nzila! Eu te saúdo!"

${ }^{4}$ Muhatu - feminino, mulher. Kaiala, Kokueto, Samba, Kaitumba são Minkisi das águas salgadas. Já Kisimbi e Ndanda Nlunda são divindades femininas das águas doces.
} 
seus conceitos brancos, na leitura de obras de arte pretas. A crítica de Munanga a respeito do pensamento de Levis-Strauss aborda justamente uma leitura rasa acerca do processo criativo e significativo da expressão artística africana. Ele argumenta que a arte primitiva africana tinha que lidar com uma tecnologia bastante rudimentar e a dificuldade de lidar com materiais de grande resistência, o que implicaria diretamente na qualidade da representação. Porém, as formas de representação africana não levam em conta a imitação do real, mas a significação do sobrenatural através do material. Não há compromisso em reprodutibilidade dos caracteres humanos, e, sim, de forças da natureza, que carregam um arquétipo do humano, com características físicas próximas do real-material.

Desse modo, o que se expressa nas estátuas, ora discutidas, é justamente a comunicação e ligação do material, terreno, com o sagrado. Arte africana é a uma das formas de conexão de toda uma cosmovisão particular. Expressar-se artisticamente para se conectar com o sagrado. Não há falhas na construção dessas materialidades, porque aqui não há um modelo específico a ser alcançado. A criação precede uma autorização sagrada para a execução, bem como o manejo de matéria prima específica. O mesmo se aplica na confecção das máscaras (Mukange) utilizadas em quase todos os rituais sociais do povo Bantu.

Particularmente a respeito destas máscaras, seu culto se perde na travessia transatlântica, e não temos registros atuais de perpetuação de ritos sociais e religiosos ligados à fabricação e uso das Mukanges. Algumas pistas nos levam a compreender o fim das Mukanges nas expressões sociais diaspóricas no Brasil. A madeira utilizada para tal não existe no Brasil, o que dificulta a confecção; o culto das mukanges não veio nos porões dos navios negreiros para o Brasil; além disto, a criação das máscaras demandava uma iniciação específica e certo tempo de reclusão nas matas, para oficializar a autorização de manejá-la. Com a perversidade da escravidão, não é difícil pensar que faltava tempo para esta atividade. Há registro de apenas um terreiro em São Paulo, Inzó Tumbansi, com o sacerdócio do Taata dya Nkisi Katuvanjesi (Walmir Damasceno), que ainda mantém esta tradição, através do vínculo direto com comunidades Bantu em Angola. ${ }^{5}$

\footnotetext{
${ }^{5}$ O Inzó Tumbansi possui uma página virtual para divulgação de sua associação religiosa e de resultados de pesquisas desenvolvidas pelos membros, disponível no endereço eletrônico: http://ilabantu.inzotumbansi.org/ acesso em: 01/03/2018.
} 
Ainda tratando desta travessia, é importante salientar que a produção artística ancestral está diretamente ligada ao sagrado. Chegando ao Brasil, nossos ancestrais negros criam o Candomblé como símbolo de resistência de sua cultura. Candomblé, palavra brasileira que parte da expressão de língua kikoonko, Bantu, Ka Nzo Ndombe sendo "ka" usado para o diminutivo; "nzo" significa casa; "ndombe" significa negros/nativos. Portanto, acredita-se que no dia-a-dia, a expressão alterou-se para $K a$ ndombe, que mais tarde tornou-se candomblé (pequena casa de negros ou espaço de reunião de negros). É impossível ignorar o candomblé como inspiração poética para a produção artística negrorreferenciada, porque um terreiro é a reconstrução de uma sociedade que foi fortemente violentada em seus valores sociais, políticos éticos, morais, artísticos e de expressão livre, de forma geral.

A perspectiva africana do terreiro, ao contrário, não surgiu para excluir os parceiros do jogo (brancos, mestiços, etc.) nem para rejeitar a paisagem local, mas para permitir a prática de uma cosmovisão exilada. A cultura não se fazia aí como efeito de demonstração, mas uma reconstrução vitalista para ensejar uma continuidade geradora de identidade (Sodré, 1988, p. 54 apud Machado, 2010, p.5 e 6$)$.

Toda esta sapiência singular garantiu a perpetuação da identidade dos povos africanos no Brasil, ainda que esta identidade estivesse esfacelada. Esta construção simbólica, mas também material, da casa de santo, guarda em seu interior a constituição de uma pequena sociedade com valores e modos de aprender bastante peculiares. A respeito disto, friso aqui que os valores estéticos são a base para a conexão religiosa, portanto fazem parte de toda a construção de valores simbólicos do terreiro.

Pensando nesta perspectiva, os valores estéticos se presentificam em todos os aspectos: música, dança, culinária, indumentária, ornamentação do barracão (salão onde as festas acontecem), a forma de expressão dos Minkisi $^{6}$ são exemplos vivos de conexão de todos os elementos. Um depende do outro para existir. Não se faz candomblé sem o som dos atabaques, sem partilhar alimentos para matar a fome da comunidade, sem vestuário adequado, sem folhas, sem conexão com a natureza, sem beleza. Tudo se torna o todo, sendo difícil particionar. Este todo gera uma atmosfera estética, que se

\footnotetext{
${ }^{6}$ Minkisi - Plural de Nkisi (espírito sagrado das forças da natureza). Relacionados aos elementos água, terra, fogo e ar. Os Bantu acreditam que Nkisi não teve vida terrena, se configurando, portanto, como uma energia superior da natureza, que se materializa num corpo de um médium devidamente preparado para receber essa energia. Neste sentido, somos contrários à filosofia Iorubá, a qual acredita que os orixás foram homens e mulheres comuns, que habitaram a terra. Por seus feitos heroicos, se destacam e ganham títulos sagrados, tornando-se eledás, orixás, deuses.
} 
junta à energia ancestral do sagrado, instaurando um campo expandido que só é perceptível através do sensível, do sentir. Muitas vezes sendo impossível expressar em palavras ou formas pré-concebidas.

Os símbolos, embora nos sejam familiares na vida diária, passam a ter importância do que é sagrado nas cerimônias rituais. Durante as cerimônias, portanto, o significado dos elementos mais simples vão além da imagem, além do que é evidente e convencional. [...] O candomblé, como se pode perceber, se caracterizava pela existência de inúmeros elementos simbólicos-sagrados que presentificam a transmissão e redistribuição de axé. Quando consagrados, acredita-se transcender à compreensão de sua estrutura física ou fenomenológica, adquirindo uma nova qualidade em força e poder. Daí é que estes elementos se constituem em representações simbólicas de conceitos, cuja definição, através da linguagem verbal, se torna quase sempre impossível. (Machado, 2002, p.46)

O universo do simbólico está impregnado em todas as coisas do candomblé, porque a filosofia Bantu assim vê a vida, de forma complexa e com todo seu arsenal de significados trançados. No terreiro, nada está ali por acaso. Tudo tem um porquê e tudo está conectado, tudo circula, tudo se ensina e se aprende. Não há distinção entre política, ciência, arte e religião, como afirma Eduardo David de Oliveira (2007, p.142):

Seja no Xirê, na roda de capoeira ou no pé do Baobá, a vivência cultural é sempre circular. A circularidade é, pois, um padrão da cultura tradicional africana. $O$ círculo tem a qualidade de não excluir e suas primeiras características são a integração e a horizontalidade. O que entra no interior de um círculo já o compõe. E tudo que compõe um círculo está integrado em roda, onde cada elemento se relaciona com o outro, complementando-o. Talvez por isso a cultura oral, praticada embaixo de frondosos Baobás, nas canções dos Griots, não separe ciência de arte, política de religião.

Na Afrocênica não vemos barreiras entre formas de conhecimento, nem mesmo barreiras cognitivas. Todos são e todos estão. Candomblé, educação, cultura, militância, arte estão integrados de tal modo que separá-los enfraquece o discurso ou invalida-o. Vale ressaltar que ao tratar de candomblé, interessa a mim seus aspectos históricos, políticos e culturais. Os segredos e mistérios são guardados nas mentes de quem viveu/participou. Portanto, a religiosidade em sua essência de culto não deve chegar até à cena.

Do ponto de vista metodológico, a Afrocênica está circunscrita na Pedagogia da Circularidade. Esta diretriz metodológica se inspira na cultura Bantu e no cotidiano do Unzó ia Kisimbi ria Maza Nzambi. Os Bantu seguem a filosofia Ubuntu, ancorada na ideia de horizontalizações das relações sociais, políticas e culturais; acesso comum a 
todos, com isto a existência individual só é possível considerando a diversidade e existência do outro. Circular, portanto, está diretamente relacionado à continuidade de um pensamento que não se esgota, mais se descarrega e recarrega naturalmente, não estando fechado para possibilidades outras; além de atravessar qualquer prática pedagógica, pela transversalidade. Perpassa, portanto, qualquer esfera social e conceitual, servindo não somente às artes, mas a compreensão do humano e sua função real na vida terrena.

Tudo está e é movimento. Nada é estável, nem fechado. As conexões gerais são possíveis, desde que horizontalize e permita o acesso de todos.

O círculo é a via instalada constantemente como estratégia metodológica para ensinar. Por sinal, ver o sagrado nos mínimos gestos e materialidades dos ritos, ajuda a perceber como não há hierarquia no processo de aprender sobre o axé. Isto dito no sentido de que não há cronologia, o conhecimento circula, como pés de uma habilidosa dançarina. Podemos falar hoje sobre rituais fúnebres, amanhã sobre batismos, e depois sobre comidas votivas, e seguir com os Muimbos. ${ }^{7}$ Essa 'forma disforme' ajuda a compreender ainda mais esse sentido pedagógico da circularidade.

A Pedagogia da Circularidade tem os seguintes conceitos-chave em sua abordagem descolonizada:

- Alteridade como condição da própria existência;

- Conexão da produção de conhecimento/pensamento com o mundo;

- Caráter holístico;

- Inspiração poética no candomblé Congo-Angola;

- Modos de pensar cíclico (retroalimentação).

Pelo seu caráter holístico consideramos a unidade do pensamento a partir da multirreferencialidade de cada um. Com isto, a palavra é publicizada, porém o respeito à coletividade deve ser mantido. Não é possível ignorar o mundo afora, fechando na vida exclusiva do terreiro/mundo. Os dois coexistem, se conectam, assim como atuantes se conectam em uma representação. E destas relações de ir e vir, circular, há uma reinvenção de si mesma, em um ciclo que encerra, porém imediatamente outro se inicia, instaurando a continuidade retroalimentada.

\footnotetext{
${ }^{7}$ Muimbos - Cânticos.
} 
A Afrocênica é um conceito em experimentação que reconhece a cena teatral integralizando as demais expressões artísticas oficiais na educação básica brasileira: dança, teatro, música e visualidades. Na verdade, há um questionamento se a Afrocênica estaria circunscrita no âmbito do teatro, propriamente dito, porque esta trata de uma expressão artística que transcende a ideia do teatro tradicional da palavra, provocando no espectador uma reflexão psicofísica e político-ideológica fomentada única e exclusivamente através da vivência pessoal e das referências ancestrais de cada indivíduo.

Ao tratar de arte africana é importante pensar nesta comunhão total de toda e qualquer expressão artística envolvida numa obra, de tal modo que não se pode separálas para compreendê-las. Portanto, a Afrocênica integraliza as expressões da música, dança, circo, literatura, teatro, sociologia, filosofia, plásticas, artes de rua, dentre outras, articulando um discurso estético multirreferencial.

O canto, a dança, a música, as vestimentas das divindades, os adereços, as ferramentas dos assentamentos (símbolos das divindades guardados nos quartos de santo) colocados nos altares, o uso das cores e das formas, os movimentos, os ritmos, os sabores e a visualidade dos pratos preparados nas cerimônias dos Orixás - tudo é símbolo de comunicação entre os humanos e as divindades, elementos que contribuem para o que podemos chamar de cenicidade do axé. (Barbosa, 2016, p.47) (Grifo nosso).

Reconheçamos o conceito de "cenicidade do axé", como sintetização da expressão Afrocênica, no sentido de comunhão total de todos os elementos do culto, trançados com um objetivo único - neste caso, a celebração aos Minkisi/vodum/orixá de determinado festejo. Façamos a correspondência do culto, com a cena, apenas como ilustração do conceito. A cena seria o partilhamento de um momento de celebração ou provocação artística com seu público. Para que esta cena se realize, faz-se necessário o equilíbrio direto entre a palavra dita, o corpo dilatado, as cores que representam a luta de resistência pelo ideal negro, os objetos sagrados e a música de levante.

$\mathrm{O}$ paralelo feito aqui entre as artes africanas e as afrodiaspóricas no Brasil, trançam-se no instante em que consideram a relação direta entre ancestralidade expressão artística - engajamento político - representação material/imaterial. Neste sentido, a conceituação de Teatro Negro da professora Evani Tavares se aproxima ao que inspira a Afrocênica, como 
[..] aquele que abrange o conjunto de manifestações espetaculares negras, originadas na Diáspora, e que lança mão do repertório cultural e estético de matriz africana como meio de expressão, de recuperação, resistência e/ou afirmação da cultura negra (Lima, 2010, p.43).

Esta definição abarca os aspectos históricos, políticos, ancestrais e estéticos das matrizes negrodescendentes. Desta forma, a Afrocênica se interessa por uma cena com pessoas negras (ou não) e/ou temáticas mitopoéticas africanas e/ou afrodiaspóricas e/ou um discurso engajado, exaltando a luta e resistência do povo negro. Tratamos de uma cena cuja poética está incensada pelo ancestral, sem perder de vista aspectos históricos de luta e resistência, engajamento e reatualização com mitos e novas problematizações da pessoa negra no status social, além de fricções entre aspectos estéticos tradicionais e novas expressões da cena contemporânea. Esta multirreferencialidade é própria desta perspectiva de pensar africana, que não concebe uma coisa por um sentido apenas.

A pesquisadora Leda Maria Martins reitera esta duplicidade - nesta tese entendida como multiplicidade - como uma característica inerente a pessoa negra, que se utiliza desta forma subversiva de pensar como estratégia de sobrevivência, sobretudo na diáspora. Pensamento duplo (ou múltiplo) que é atestado na criação do sincretismo, como ação de resistência do sagrado nos cultos; bem como na Capoeira, dançada com roupas de ir à missa aos domingos, para não "levantar suspeitas" do colonizador; ou ainda nos versos dos sambas de roda, com as expressões de duplo sentido, reafirmadas na repetição melódica dos versos. Além disto, a duplicidade intertextual e intercultural amalgama a noção de estar no mundo e se relacionar com este. Com a diáspora, a reconexão precisou ser feita, para que a única dignidade, não arrancada dos povos, permanecesse - a capacidade de pensar.

Esta pesquisa compreende o conceito de Afrocênica considerando esta cena aberta, do ponto de vista de representação das artes de modo integrado, na qual não se pode dizer que tratamos apenas do teatro, ou da dança, mas do trançado dos modos de pensar e fazer próprios dos povos africanos subsaarianos, os quais conectam as expressões estéticas em um acontecimento, sempre considerando algum ritual social, com um discurso provocativo, impactante, sobretudo do ponto de vista das visualidades, e de uma grande capacidade de envolvimento cósmico e conexão com uma força ancestral sagrada que circula no instante da dilatação dos corpos e diálogo com demais expressões da cena. Neste instante, na panela são adicionados o mito, memória, 
oralidade, corpo e expressão, como produto da dilatação das expressões da cena citadas, que justapostos possibilitam que a Afrocênica se inscreva.

\section{CAMPO NEGRO EXPANDIDO: PERFORMANCE/TEATRALIDADE/CANDOMBLÉ/CENA PRETA}

É perceptível que a expressão cultural dos Bantu está muito próxima das manifestações da performance/performatividade, sobretudo no campo das Teatralidades (Féral, 2002). Nessa confluência de referências, entendo que no campo da performance e das teatralidades há espaço para este diálogo com a cultura Bantu afro-brasileira. O desejo agora é cruzar esses dois universos tão próximos e tornar uma potente cena afrodiaspórica.

A este respeito, faço agora uma aproximação da "cenicidade do axé" com as epistemologias da performance/performatividade/teatralidades como campo expandido.

A ideia de circularidade já posta não é novidade quando o assunto é Teatro. Desde a Grécia, com os rituais religiosos, percebemos que o grande momento de exaltação aos Deuses, mais especificamente Dionísio, culminava numa relação circular. Dessas relações de religiosidade carregada de estética - a exemplo do candomblé - o teatro se configura. Do grego, Theatron (lugar onde se vê), com isto começamos a desenhar esse pensamento do que é de fato a teatralidade. Iniciar com este conceito da visualidade, do que se vê, como se vê, porque ou por quem se vê, são os primeiros vestígios que me impulsionaram a refletir sobre minha prática enquanto professor/encenador. Sílvia Fernandes, em diálogo com o pensamento de Pavis nos diz que:

[...] Para um espectador aberto às referências da cena contemporânea, a teatralidade pode ser uma maneira de atenuar o real para torna-lo estético; ou um modo de sublinhar esse real com um traçado cênico obsessivo, a fim de reconhecê-lo e compreender o político, ou um embate de regimes ficcionais distintos que impede a encenação de construir-se a partir de um único ponto de vista, e abre múltiplos focos de olhar em disputa pela primazia de observação de mundo (Fernandes, 2011, p.12)

A primeira reflexão importante do texto, diz respeito à atenuação do real, na conversão de novos caracteres contemporâneos da cena em estética, no belo, na consumição direta dos nossos sentidos. Pensando nos dias de hoje, desde a infância já estamos bombardeados de estímulos diversos os quais educaram os nossos olhos através de uma perspectiva mais amplificada da possibilidade variada de ler o mundo. O 
advento da internet, a modernização dos aparelhos celulares, cujas novas funções são equivalentes a um computador, permitem conexões em tempo real com diversas culturas e pensamentos no mundo. O que antes era impossível de pensar, hoje é uma realidade; o acesso à informação e à imagem é assustador. E o que mais me assusta é como jovens, ainda na primeira infância, se relacionam com grande intimidade com essas novas tecnologias.

Com a queda dos muros do dramático como essência do teatro ocidental, a cena se expandiu, como já relatado, envolvendo o espectador no espetáculo. Essa "revolução" na verdade já existe desde que o teatro foi sistematizado pelos gregos, mas só ganha novos olhares com a poética de Bertolt Brecht, quando este derruba a tal quarta parede da sua cena, permitindo que o público entre no espetáculo, seja ele próprio um dos criadores. Neste caso, a poética brechtiana se vale de valores políticos para discutir sua cena declaradamente social, como vê Robert Brustein (1967) em seu Teatro de Protesto. A ficção está aqui a favor do discurso estético, cênico e político. A cena teatral dilata-se a tal ponto que a ficção e a realidade dividem a mesma fronteira, porque não interessa o 'como', mas 'o quê' passa, o que toca, a experiência deste saber, conforme escritos de Jorge Larrosa Bondía (2002).

O que está em questão é a própria crise do teatro, que se arrasta desde sua existência até os dias que seguem. As teorias de Peter Szondi, Jean-Pierre Sarrazac, Hans-Thies Lehmann, dentre outros autores, erigiram pensamentos acerca dessa crise que nunca chega ao fim. Nas fronteiras da crise conceitual declarada, segue a Teatralidade, a Performance e a Performatividade.

Fernandes compreende a Teatralidade como um campo polissêmico, incluindo a performatividade e depende da leitura do espectador para se construir (2011, p.12). Por isto, há tantos embates epistemológicos acerca dessas fronteiras, mas o detalhe para o entendimento será, certamente, a abordagem que cada vertente se debruça. Obviamente que esta abordagem em ambas as três significações da expressão artística Teatralidade, Performatividade e Performance - depende da significação da experiência de quem por elas foram atravessadas. No embate sem vitória, estão as primeiras fronteiras de Performance e Performatividade. Sobre o primeiro, do inglês entende-se "performance" como desempenho, como algo inacabado, em construção, em ação. A professora Mariana Simoni Machado, se apropriando dos conceitos da autora canadense Josette Féral, adensa o debate: 
No âmbito desta definição, Féral contrasta de maneira não dicotômica a noção de performatividade com a de teatralidade - esta última mais ligada ao drama, à estrutura narrativa, à ficção e à ilusão cênica, que depende do olhar oscilante do espectador para tomar consistência - a partir das três conotações conferidas por Schechner para o verbo performar na língua inglesa: de acordo com a primeira delas, to perform equivale a ser (being), viver, se comportar; conforme a segunda, este verbo corresponde a fazer (doing), atividade de tudo que existe. E, por fim, sob a perspectiva da terceira conotação, to perform refere-se a mostrar o fazer (showing doing). Este último sentido identifica-se, nesta ótica, com a base da teatralidade. (Machado M., 2002, p.05)

Para Féral (2002) não há distinção entre a perfomatividade e a Teatralidade, porém a ênfase maior dada Teatralidade, será aqui relacionada às artes cênicas, por reconhecer elementos da narrativa na construção estética desta "pseudo cena". A propósito, no seu artigo Theatrical: the specifity of theatrical language (2002), ela expõe três categorias de cena na tentativa de tecer motivos pelos quais as fronteiras estão traçadas entre os termos e como a Teatralidade não está inscrita na cena teatral, todavia, de algum modo, se vale dos conceitos bases de cena para o entendimento. $\mathrm{Na}$ verdade, ela chama seus exemplos de scenario 1,2 e 3 . No primeiro ela pede para que imaginemos sentados em frente a um palco de um espetáculo que irá iniciar. Cortinas abertas, a peça não começou e os atores estão ausentes. Féral fala que o espectador já realizou sua leitura teatral desta cena. Ele tem a capacidade de ler os signos todos que ali estão alocados - "ele sabe o que esperar do desenho da cena - o jogo" 8 (ibid, p.96, tradução nossa).

No segundo scenario ela traz um exemplo de um homem fumando num trem, e outro passageiro reclamando furioso a respeito disto. Em dado momento o trem para e a porta se abre em frente a uma placa que adverte a impossibilidade de fumar ali. $\mathrm{O}$ debate se adensa. Pessoas observam esta cena. Ela pergunta se não há Teatralidade ali? Houve decodificação dos elementos cênicos, porque houve público e houve atores, ainda que estes não saibam ou não tenham a intenção de. Ela cita Boal nesta passagem, ilustrando este episódio como Teatro do Invisível ou Invisible Theatrical Production.

Podemos concluir que, neste caso, a teatralidade parece partir da percepção do espectador de uma intenção teatral dirigida para ele. Essa consciência alterou a maneira

\footnotetext{
8 "he know what to expect from the scenic design - a play".
} 
em que ele olhou para o lugar que estava falando; forçou-o a ver o teatro onde antes ele só viu uma ocorrência casual (ibid, p.96, tradução nossa) ${ }^{9}$.

A autora acredita que a noção de Teatralidade é inerente ao homem. Vemos uma simples cena no cotidiano e temos a capacidade de reconhecermos esta, sem nem conhecer os conceitos de base para a existência de uma cena, portanto a noção de Teatralidade como prática recorrente da natureza humana é mais fácil de ser despertada, do que a fruição de uma obra teatral seja ela qual for. O que também não impede que façamos a leitura de uma representação teatral. Segundo a autora, a performatividade estaria alocada no mesmo âmbito. Porém, ela reconhece nesta fronteira uma diferença clara, já citada entre ambas, afastando-as em categorias diferentes pela proximidade ou não do uso de narrativas. O que não cria uma regra estática de que toda Teatralidade seja cerceada por uma narrativa. O que quero dizer é que há mais inclinação para construção através de uma narrativa, seja lírica, épica ou dramática, ou a mistura dos três conceitos bases, ou o entrecruzamento, ou a interdependência, nesta construção imagética. Não importa muito a estrutura. Importa pensar nessa prerrogativa do flerte com a narrativa.

A respeito do conteúdo da Perfomance, Fernandes (2011, p.16) nos diz que “[...] a performance nunca é objeto ou uma obra acabada, mas sempre um processo, por estar ligado ao domínio do fazer e ao princípio da ação. Neste caso, a performance seria aquilo que vem transcender o conceito do teatro, descolar a alma do corpo cênico, para que esta alma seja outro corpo. Fazendo uma analogia a Pedagogia da Circularidade, é possível dizer que a performance caminha pelas mesmas trilhas, já que se interessa pelo contínuo. Ainda é possível dizer que a performance está no teatro, no processo de materialização da representação, mas o teatro não está na performance, por que a este não interessa o inacabado; o teatro se instaura na instabilidade do presente que é finalizado a cada instante e só este existe no tempo, segundo Ricoeur (2010), ao refletir sobre o pensamento de Agostinho, seria o "Triplo Presente". Agostinho diz que: "o presente do passado é a memória, o presente do presente é a visão [depois chamada de atenção] e o presente do futuro é a expectativa" (Confissões, 20, 26 in Ricoeur, 2010).

\footnotetext{
9 "We might conclude that in this instance, theatricality seems from, the spectador's awareness of a theatrical intention addressed to him. This awareness altered the way in which he looked at what was talking place; it forced him to see theater where before he saw only a chance occurance".
} 
Agostinho vai dizer que a memória e a expectativa estão suspensas na alma, restando apenas a atenção, porque tudo automaticamente será passado. Por esta razão o teatro não pode estar circunscrito na performance, pois a realização da representação está sendo feita e só interessa aquele momento. Quando esta acabar, outra iniciará. Não há como registrar este tempo, partindo dos princípios de Agostinho. Nem há como registrar o tempo no candomblé. As vivências são únicas. Nenhum rito acontece de forma idêntica ao outro, apesar de utilizar os mesmos elementos, mantendo a tradicionalidade. Mas, a Performance também não dá conta de estar no passado, preferindo expor ao público o presente do passado acontecendo no presente. É como se abrisse o interior de uma máquina em atividade, e víssemos apenas as engrenagens sendo lubrificadas por óleo, e algo sendo construído neste instante. Quando as engrenagens param, o que importa para a performance é o que já foi visto: algo sendo criado. O teatro se imbui de mostrar com detalhes o que está sendo criado e o que foi produzido como objeto desta criação. A Performance pode interromper esta última etapa, porque a ela é desinteressante. O objeto desta criação não é o foco. O que importa para a Performance é justamente o trajeto.

A Performance, ao se aproximar da representação, descola-se desta e ganha outra forma de ser vista/percebida/compreendida. A Performatividade estaria na linha tênue do descolamento da alma do corpo. Assume caracteres do teatro e da via contrária da performance. De algum modo, a Teatralidade se aproxima da Performatividade neste instante.

A Teatralidade repousa no campo de uma pseudo representação simbólica, ainda que não necessariamente pertença ao teatro. Já a performance, segundo Fernandes se expressa numa rede de impulsos (2011, p.18). Esta rede de impulsos gera um campo simbólico de expressão, efetivamente instaurado na materialidade física do ambiente, o que Ileana Diéguez (2014) chama de campo expandido. Ela diz que deste campo expandido, na fronteira da performance e da representação teatral, emerge a Teatralidade.

De algum modo este pensamento se justapõe ao de Féral (2002, p.16), quando ela insiste em dizer que a leitura da Teatralidade dentro das manifestações humanas é possível de ser experienciada pelo homem de forma natural: "Os objetos com sua imponente presença, tomaram espaços e produziram uma presença cênica que demandava atenção ou expectativa". Esta observação foi feita pela autora, quando esta 
fala da instalação de objetos que se descolam das paredes brancas dos museus, forçando os pintores a reconsiderarem sua forma de expressão. Todavia, é interessante pensar na necessidade de atenção que a Teatralidade demanda e se faz presente. Campos expandidos se formam e somos capazes de senti-los, ainda que não inscritos dentro de espaços convencionais de representação. Isto por que: "a teatralidade é uma disposição complexa e mutante, [...] não redutível à cena nem a interpretação de um dado prévio" (Diéguez, 2014, p.125) - é uma condição do homem ver, perceber o teatral.

Pensando nesta complexidade da noção do campo expandido proposto por Diéguez, consigo estabelecer um paralelo com o candomblé, com o terreiro/templo. Ao passar da porteira, portão principal da entrada, ali já se instaura um campo negro expandido, através do qual o visitante/espectador já está circunscrito na cena/cotidiano do axé, diante de objetos/casas/cheiros/cores/folhas/indumentárias específicas que o envolvem num campo de atenção e reflexão constante, sem que este se desse conta da atmosfera expandida que o envolve. Neste sentido, é possível dizer que "[...] o processo de integralidade do pensamento africano, que não sedimenta o conhecimento, oportunizando ao indivíduo um contato global tanto com os elementos materiais da natureza quanto com as realidades espiritual, simbólica e social" (Barbosa, 2016, p.47).

Imerso no campo negro expandido, amplia-se a noção complexa de mundo, extrapolando os valores de sua vida particular, com a pulsação do mundo. Relacionando a nossa Afrocênica, imagina-se, rapidamente, que esta condição primeira dos elementos culturais do axé sejam facilmente reconhecíveis, em seu campo negro expandido, através de uma representação cênica.

Ter a capacidade de envolver o público em uma conexão cênica/artística/espiritual/simbólica potencializa o discurso a ser proferido nos espetáculos. Deste modo, é interessante engrossar o caldo político de reivindicação do lugar do negro na sociedade, pelo fim do racismo, problematizando questões gerais, ou até mesmo existenciais que garantem ou furtam a liberdade de ser negro no Brasil.

\section{DA POESIA PRETA: MODOS DE FAZER, PENSAR, EXPRESSAR, REPRESENTAR}

Quando falo de tradição não me refiro a algo congelado, estático que aponta apenas à anterioridade ou antiguidade, mas aos princípios míticos inaugurais, constitutivos e condutores de identidade, de memória, capazes de transmitir de geração a geração a continuidade essencial, e ao mesmo tempo, reelaborar-se nas diversas circunstancias históricas, incorporando informações estéticas que 
permitam renovar a experiência, fortalecendo seus próprios valores (Mestre Didi, 1989).

A tradição aqui posta pelo Mestre Didi transcende a noção de passado estanque, ressignificando seus valores enquanto presentes na contemporaneidade, a partir de uma nova estética e modos de ser, porém, sem esquecer as raízes que motivaram a sobrevivência dos povos na contemporaneidade. Esta continuidade é viva na cena teatral contemporânea por alguns grupos teatrais, os quais ainda reconhecem a importância em exaltar estes valores ancestrais para nutrir forças para o discurso político engajado nas poéticas negras dos dias que seguem.

Posto este universo pedagógico circular já mencionado, considerando o campo negro expandido instaurado, se faz interessante pensar nas encruzilhadas que levam a este estado de cena. Diretrizes serão traçadas para se pensar na construção de um discurso cênico que privilegie determinados caracteres a serem listados:

a) Ativação da Memória Corporal Africana/corpo ritmado/corpo-dança e discurso político;

b) Mito-poemas e matrizes narracionais em cena;

c) Musicalidades instauradora de presença/visualidades e simbologias ancestrais.

Estas investigações não necessariamente seguem esta ordem em seu processo de experimentação cênica e formação artística. Não importam os caminhos, nem se faz necessário o domínio completo dos atuantes em todos os segmentos. O que se percebe é o entrecruzamento destes aspectos ao reconhecer a Afrocênica como preparação conceitual e prática para a cena diaspórica.

\section{ATIVAÇÃO DA MEMÓRIA CORPORAL AFRICANA/CORPO RITMADO/CORPO-DANÇA E DISCURSO POLÍTICO}

Considerando o corpo/história/herança ancestral, ao se experienciar a Afrocênica, o exercício da autorreflexão é constante, estando o corpo em evidência, ele será o primeiro a ser ativado. Ele é o cavalo ${ }^{10}$ para transportar o artista cênico para

\footnotetext{
10 "Cavalo" é uma expressão utilizada nas comunidades de terreiro para relacionar diretamente a pessoa que incorpora, que tem mediunidade de incorporação de espíritos, neste caso, que "vira" no orixá/Nkisi/vodum. Expressão comumente falada pelos caboclos, espíritos ancestrais dos índios, boiadeiros que viveram no país e hoje, no plano espiritual, atuam como conselheiros, curandeiros, guias e protetores espirituais de nós, seres viventes do Brasil.
} 
universos míticos, ancestrais, políticos e crítico-sensível. A respeito deste corpo a ser ativado para a cena, Barbosa (2016, p.98) chama de corpo templo:

O corpo templo, no sentido religioso, é um corpo preenchido pelas forças cósmicas em contato íntimo com a divindade. No sentido teatral, é um corpo tomado, conectado com a ancestralidade, ciente de uma identidade cultural e em estado de prontidão, dilatação cênica e irradiação energética.

Este corpo é símbolo de libertação política, de expressão de um ser dotado de identidade, com toda sua complexidade distante do desgracioso processo histórico de objetificação do ser negro. Corpo dilatado em cena, que permite comunicação direta a partir de sua natural expressão ancestral. Este corpo apresenta a característica de responder a estímulos rapidamente, em estado de prontidão, obedecendo a uma cadência particular, prevalecendo a expressão ritmada.

A boca é um órgão muito especial, ela simboliza a fala e a enunciação. No âmbito do racismo a boca torna-se o órgão da opressão por excelência, ela representa o órgão que os(as) brancos(as) querem - e precisam - controlar e, consequentemente o órgão que, historicamente, tem sido severamente repreendido (Kilomba, 1997, p.172)

Com licença poética dos escritos de Grada Kilomba, imagino esta boca como todo um corpo ancestral, através do qual a necessidade de expressar-se é urgente, tornando este corpo/boca livre das amarras e grilhões que o aprisionaram por duros anos. Um corpo negro em cena não mais se submete a sensualização e violência enquanto estado de prisão. Ao ver um corpo/boca negra em cena, vê-se um discurso político anterior à própria expressão, bem como uma ancestralidade que protege e retroalimenta seu estado de prontidão e vigor na cena.

Este corpo negro ativado, com o auxílio potente da musicalidade que pulsa no interior dos capilares sanguíneos, impulsionando as batidas do coração, sem dúvidas se organiza de forma dual, com firmeza e delicadeza, com precisão e desequilíbrio, com cadência e descompasso, de acordo com a necessidade de comunicação cênica ou de relação com a sociedade. Este corpo dança, muitas vezes sem dançar. Dança porque existe, porque a necessidade de fazer este corpo manter-se vivo é através da coreografia orgânica de seu corpo, movimentos peristálticos, contrações involuntárias dos órgãos, o fluxo do sangue correndo nas veias, até mesmo em se deslocar no espaço.

Sendo veículo no processo de instauração de sentido, Exu estrutura a enunciação própria do negro nas Américas. Sua natureza histriônica permite-lhe operar várias 
metamorfoses, sem, contudo, deixar de ser ele mesmo, sem perder sua originalidade. Essa característica metamórfica, essa ginga (o mancar de Exu), é um elemento essencial na arte de teatralizar do negro. Exu simboliza, assim, um mitema retórico, religioso e dramático, no qual se apoiam algumas formas próprias da cultura negra, na encruzilhada mesma dos discursos que essa cultura opera (Martins, 1995, p.57).

Esse corpo é também um corpo-Exu, pensando o arquétipo desta divindade iorubá como o estado de prontidão desejado nos corpos destes intérpretes que se propõe a experimentar uma Afrocênica. Exu está sempre preparado para ir e vir, viajar, sumir, reaparecer, comunicar, trazer de volta, levar. Estas qualidades de movimentos são aplicáveis ao corpo dos intérpretes, auxiliando ao processo de metamorfoseamento da cena preta. Metamorfose que passeia por qualidades diversas de movimentos, desde a histeria com o estado máximo de dilatação do corpo, em comunhão com o ritual instaurado - em equilíbrio com a música, as visualidades e a energia que toma o ambiente - até o corpo-silêncio, que não se deixa ser silenciado, ainda que a boca nada diga. É um corpo-repertório. Corpo-encruzilhada, com muitas possibilidades e se emprestando completamente ao jogo de cena, na certeza de que seu corpo não é só um corpo, mas o atravessamento de religião-política-cultura-arte.

\section{MITO-POEMAS E AS MATRIZES NARRACIONAIS}

Muitas civilizações desenvolveram seu próprio repertório mitológico, que também cumpria a função de educar seu povo através da moralidade implícita no mito. Infelizmente, as muitas mitologias africanas jamais foram divulgadas, sobretudo no âmbito escolar, prevalecendo a Mitologia Grega e Romana, como referências no Brasil.

Aos mitos é possível atribuir também o valor da crença, da fé de seu povo, logo a sua relação é de fundamental importância, porque está relacionado ao modo de vida, ao sagrado, a acordos sociais de ética e moral. Junito de Souza Brandão (2010, p.37) traz o conceito do mito como o relato de um acontecimento ocorrido no tempo primordial, mediante a intervenção de entes sobrenaturais.

Existem vários significados para a mitologia. Brandão (ibid, p.40) inicia com o conceito de mitologema, caracterizando com a soma de elementos antigos transmitidos pela tradição e mitema as unidades constitutivas desses elementos. A mitologia seria justamente o 'movimento' desse material - o estável e mutável simultaneamente, sujeito, portanto, a transformações. 
Se considerarmos a etimologia da palavra mitologia encontraremos a mesma como o estudo dos mitos, concebidos como história verdadeira. Já a religião pode ser considerada como um conjunto de atos e manifestações que cumpre a função de ligar o homem ao divino, numa relação de dependência de seres invisíveis, ditos sobrenaturais. A religião está ainda na relação de completar o que falta ao homem, dar sentido à vida, alimentando-o com sensações que não se podem ter com elementos materiais. Ela dá o que não se pode ver, apenas sentir. Essa relação é bem próxima da relação mitológica, no instante em que explicações são dadas para atitudes e ações que não se explicam pelas vias naturais, dentro daquilo que está na normalidade, com comprovações científicas.

Brandão (2010) ainda reitera que "a religião para os antigos é a reatualização e a ritualização do mito. O rito possui, no dizer de Georges Gusdorf, o poder de suscitar ou, ao menos, de reafirmar o mito" (ibid). Isso porque através do rito o homem se incorpora ao mito, ele se transpõe às suas origens, canalizando à sua alma toda a energia e força que é possível extrair dessa relação.

No rito ainda é possível transcender o mito, encontrar uma relação direta entre o sagrado e o profano. Acredito na ideia que a ritualização do mito contextualiza-o e o faz mais forte, porque considera a realidade atual da cosmovisão. Isso porque não podemos perder de vista a noção de que a mitologia atravessa gerações, conseguindo chegar à contemporaneidade.

Ainda na relação existente entre o mito e o rito, percebemos outra relação crucial estabelecida entre o tempo. Nos rituais não é considerado o tempo profano, recuperando, assim, o tempo sagrado. Justamente porque o tempo cronológico é linear e irreversível (você pode comemorar uma data histórica, mas não pode fazer volta-la no tempo).

Nessa recuperação do tempo sagrado percebemos uma relação circular, na qual o tempo sempre volta sobre si mesmo. Justamente essa relação de circularidade estabelecida nos rituais que confere ao homem a possibilidade de libertação, de ir e vir, de religa-lo com aquilo que não seria possível através das vias profanas. O homem consegue abolir o passado, reconfigurar seus caminhos para construção de um futuro azado. Brandão (2010, p.42) diz que o profano é o tempo da vida; o sagrado, o "tempo" da eternidade. 
Outro ponto a ser considerado no presente trabalho é a questão da oralidade que está imbricada nas relações entre mito e rito. Nos escritos de Vanda Machado (2002, p.84) ela afirma que os mitos são ensinados e vivenciados ritualisticamente no processo de iniciação e ao longo da vida. Diz ainda que esse conhecimento transmitido atende a necessidade de quem aprende, portanto é algo desejado, não fragmentado.

Igualmente, a comunicação, o aprendizado desses ensinamentos quase sempre é transmitido na tradição oral. Tanto na Grécia, com as tragédias Gregas encenadas por atores, num palco, quanto na África, com a ritualização do culto aos orixás, é possível perceber que uma tradição do oral se consolidou, no empenho de manter viva a tradição mitológica no social.

A propósito, acerca destes trancamentos, observamos esta tendência em utilizar mito como poemas e permanecer viva a tradição da oralidade enquanto condição primaz para a comunicação cênica na perspectiva Afrocênica. Mito e rito constituem a base da narrativa das poéticas afrodiaspóricas no Brasil, estabelecendo, assim, além da expressão através do corpo, uma comunicação estreia pelo que sai da boca deste corpo, enraizado, quase sempre, na relação com o sagrado, místico e sobrenatural, como matriz de sabedoria que conduz as práticas sociais para as comunidades afrodescentes.

A pesquisadora Íris Maria da Costa Amâncio (2015), em seu livro Teatro Angolano: dramaturgia, literatura e representações de etnicidade, aponta, logo de início, a importância das vivências dos angolanos que chegam à cena dos dramaturgos Domingos Van-Dúnem (1970), potencializado por José Mena Abrantes (1990-2018), junto com o grupo teatral angolano Elinga-Teatro, com a forte presença das raízes e matrizes narracionais orais nas narrativas literárias angolas. ${ }^{11}$ A autora destaca a capacidade dos autores em trazer a cena, trançada na trama cênica, essas vivências de tradições étnicas orais, presentes no imaginário popular de Angola. Estamos falando aqui de um teatro contemporâneo, porém ancorado em temas tradicionais de Luanda. Percebe-se que, de fato, não há como tratar de teatro/cultura em Angola sem fugir a premissa da tradição ancestral oral.

\footnotetext{
${ }^{11} \mathrm{O}$ grupo Elinga-Teatro (do umbundo 'elinga', que significa ação, iniciativa, exercício) foi criado no dia 21 de Maio de 1988. Pelas condições de trabalho, o grupo se considera amador, com uma produção de 28 anos. A sua existência inscreve-se, no entanto, numa linha de continuidade iniciada com o grupo Tchinganje (1975/76) e prosseguida com o Xilenga-Teatro (1977/80) e com o Grupo de Teatro da Faculdade de Medicina de Luanda (1984/87), ambos dirigidos pelo português José Mena Abrantes. O trabalho do grupo está voltado para a promoção da cultura angolana a todos os níveis, incluindo um tratamento moderno dos seus valores tradicionais, e para a difusão de um repertório teatral universal.
} 
A mesma realidade é perceptível no grupo NATA (Núcleo Afro-brasileiro de Teatro de Alagoinhas, 1998) ${ }^{12}$. As montagens carregam forte matriz narracional, ancorada nas suas bases mito-poéticas, que transcendem os temas tradicionais dos africanos, a partir da cosmovisão Yorubá, para ampliar o discurso englobando questões gerais concernentes à contemporaneidade.

A respeito do universo mítico, o NATA lida diretamente com esta base poética, assim como o Elinga-Teatro. Neste caso, os

Mitos são pistas para as potencialidades espirituais da vida humana. Eles ensinam que você pode se voltar para dentro, e você começa a captar a mensagem dos símbolos [...] O mito ajuda a colocar sua mente em contato com essa experiência de estar vivo. (Campbell, 1990, p.17)

Ao mito lhe cabe a função, além de outras, de conexão com forças que não se podem descrever, apenas sentir; o mito ajuda a comunidade no processo educação, fornecendo as crianças e jovens as primeiras noções de pesquisa, quando se defrontam com um mito e precisam desvela-lo, para compreender o ensinamento ali alocado. Do ponto de vista da inspiração poética da cena, Barbosa esclarece o seu processo criativo no grupo NATA:

Assim sendo, o NATA considera as narrativas mito-poéticas pontos de partida para a construção cênica; elas apresentam, entre outras coisas, o ser, o fazer, o pensar da cosmogonia africana e afro-brasileira. São narrativas que integram parte do universo simbólico africano e sua visão de mundo. Em se tratando de um fazer cênico afirmativo, que busca um amplo conhecimento da história e da cultura africanas e afro-brasileiras, compreendemos a necessidade e a importância de um mergulho nessa mitologia; e, sendo o Candomblé um dos espaços de salvaguarda dessa herança, ele é, portanto, nosso ponto de partida para esse intento. É através do modo como o Candomblé nos apresenta essas narrativas que construímos o nosso fazer artístico (Barbosa, 2016, p.88).

Já o grupo Bando de Teatro Olodum (1990) aborda em sua poética mitos contemporâneos de luta e resistência do negro que tem sua palavra silenciada nos dias

\footnotetext{
${ }^{12}$ O NATA - Núcleo Afrobrasileiro de Teatro de Alagoinhas, inspira-se nos orikis e usa teatro, dança afro e música para mostrar a beleza e a filosofia do culto às divindades, utilizando a mitologia iorubá como inspiração mito-poética, além do candomblé com sua cenicidade de axé. Nasceu no ano de 1998 no interior da Bahia, mais precisamente na cidade de Alagoinhas, sendo guiado pelas mãos da encenadora e Ya kekerê do Ilê Axé Oyá l'Adê Inan, Fernanda Júlia Onisajé. Apesar de alguns espetáculos do grupo não terem a temática Afro, o grupo tem essa temática como norteadora do discurso estético e político com foco de colaborar na luta contra o racismo e na desmistificação da imagem negativa que a mídia reproduz das religiões e costumes afro brasileiros. Alguns espetáculos: Sirè Obá: a festa do Rei (2009), Ogum: deus e homem (2010) e Exu: a boca do universo (2014).
} 
que seguem. ${ }^{13} \mathrm{O}$ repertório mito-poético do Bando enaltece o negro nas suas problemáticas atualizadas, protagonizando a cena, devolvendo seu lugar de existência. O Bando trabalhou com textos de dramaturgos consagrados, porém sempre alterando a perspectiva de pensar a representação original, contextualizando com os ritmos africanos, corpo-dança gingado e forte discurso politizado de combate ao racismo e desigualdades.

\section{MUSICALIDADES INSTAURADORAS DE PRESENÇA/VISUALIDADES E SIMBOLOGIAS ANCESTRAIS}

Ao tratar da importância da musicalidade afro em cena, estou ratificando esta como principal responsável por transformar a atmosfera do espaço cênico, seja no processo criativo, ou na cena pública, por assim dizer. Neste caso, as batidas de tambores, xequerês, agogôs, dentre outros, com sua estrutura rítmica cadenciada, aceleram as batidas do coração e com isto, aumentam o nível de circulação sanguínea, trazendo ao nosso corpo um status energético intenso, que abre portas para a criação, reflexão e ação imediata.

Os três grupos apontados nesta pesquisa utilizam fortemente o elemento percussivo executado ao vivo, como delineamento poético e de construção do campo negro expandido. O Grupo NATA e Bando são os destaques, por trazerem o trabalho de Jarbas Bittencourt, que assina a trilha dos grupos, marcando os espetáculos sempre com uma trilha sonora contemporânea, na qual se podem ver o equilíbrio e o atravessamento entre os elementos tradicionais africanos e as reverberações destes elementos nos dias que seguem.

Nesta categoria vale salientar o trabalho vocal dos atores e atrizes, os quais também partem de um viés descolonizado de pensar a voz, inspirando-se nos cânticos dos orixás e de como essas musicalidades ressoam nos seus corpos, potencializando sua interpretação. Como argumenta Barbosa, nos processos criativos do NATA:

Já a pesquisa vocal é desenvolvida por meio de um estudo sobre o idioma yorubá, os cantos aos Orixás e a junção desses elementos ao universo da música

\footnotetext{
${ }^{13}$ Surgido no segundo semestre de 1990, estreou nos palcos de Salvador em janeiro de 1991. O Bando tem seu teatro enriquecido pela experiência dos diretores Márcio Meirelles e Chica Carelli, do coreógrafo Zebrinha e do diretor musical Jarbas Bittencourt, que dão base estética à linguagem do Grupo. Formado atualmente por 20 artistas negros de diferentes gerações. Suas peças mesclam humor e discussão racial, leveza e ironia, diversão e militância. Além da palavra, os atores utilizam a dança e a música, referenciais rituais do Candomblé e se embriagam na fonte da cultura afro-brasileira.
} 
negra brasileira, cubana e norte-americana. Nesse processo de preparação, conseguimos trabalhar os elementos ancestrais da cultura africana e suas reverberações na contemporaneidade, aprofundando esse binômio CandombléTeatro sem nos afastar das discussões sobre o fazer cênico atual. (Barbosa, 2016, p.98)

O trabalho de criação músico-vocal, aliado a uma representação visual complexa, com combinação de cores, texturas, estampas, adereços com inspiração ancestral, maquiagens apropriadas à pela negra, figurinos inspirados nos corpos particulares de seus pares e uma luz que revela a pele negra em cena, conferem a Afrocênica um ritual de intensa troca energética, debates políticos e imersões sensíveis no mais íntimo de seu corpo-mente.

O silêncio também traduz uma música de profunda representatividade para o povo negro, sobretudo na diáspora, instante em que nossas bocas foram caladas muitas vezes, seja de modo literal, com amarras, estruturas de flange, ou mesmo no gesto de impedir que nossa voz saísse de nossas bocas. Portanto, se deparar com uma cena em que o silêncio é a música que toma nossos corpos, estabelecendo rapidamente profundas reflexões ancestrais, não é difícil reconhecer sua profundidade ao retratar ciclos importantes da história de nosso povo. Mas o calar da voz não implica necessariamente na improdutividade de discurso. O silêncio é a espera da religação do sagrado com os ritos terrestres. Em um terreiro há cerimônias em que o silêncio é a condição para que determinado Nkisi participe do culto. Caso contrário, ele retira sua presença, fazendo com que todo empenho e amor devotado, perca o sentido. No silêncio se escutam as vozes ancestrais. O silêncio ensina os povos africanos. O silêncio é parte do processo de ensino-aprendizado das religiões de matrizes africanas. Você só está autorizado a falar, quando sua palavra realmente for importante, estiver amparada de sentido real, com respaldo da ancestralidade do lugar. Isto leva tempo. Por isto, se faz necessário ouvir e calar. Aprender com quem já caminhou na estrada antes de você. Com isto quero levantar a problemática do silêncio como música também instauradora de presença.

Temos música nos adereços, colares de miçangas que dançam, cantam. As saias que friccionam com as anáguas. Os balangandãs nos braços, idés, pulseiras. A esteira que desce/sobe ao chão no sambilè ${ }^{14}$. Temos música na folha que cai no chão, na pemba $^{15}$ que voa, na incenso que queima e perfuma. Temos músicas para acordar, para

\footnotetext{
${ }^{14}$ Sambilè - o mesmo que barracão. Onde as cerimônias Bantu acontecem. Grande salão de festas.

15 Pemba - um Nkisi que abre mão de sua representação e possibilidade de conexão física com um médium iniciado no culto de Angola, para ser um pó mágico, cobrir as cabeças e proteger o povo.
} 
dormir, para comer, para pedir, para agradecer, para clamar, para se arrepender, para curar e apara devotar. Não existe poética africana sem música que diretamente implicada na criação de um campo negro expandido.

\section{PAÓ}

Circularei por muitas temáticas, atravessarei muitas encruzilhadas e mares/rios/águas e talvez não consiga sintetizar de fato este conceito ainda em construção. Todavia, o que fica aqui é a reflexão acerca de uma parte da produção poética de nossos artistas negros, do ponto de vista da cena teatral. Poética esta carregada de um forte discurso questionador do nosso lugar furtado no mundo, insistindo em apagar nossos nomes, nossas crenças e querendo nos convencer de que não somos produtores de conhecimento, quiçá produtores de arte (quase sempre registrada como formas de expressão rudimentar).

Este trabalho se afirma justamente por pensar a complexidade do pensamento africano, considerando a filosofia Bantu, em particular, no desejo político de também divulga-la no meio acadêmico e social. Os povos Bantu foram os primeiros a pisar em terras brasileiras, preparando o terreno para as demais etnias africanas chegarem aqui. Com isto, muita coisa da produção artística vem deste berço multirreferecial, com mais de 256 línguas faladas e uma pluralidade cultural profunda.

Arte negra tem sua origem ritual sim, sobretudo uma arte que compreende sua expressão a partir da comunicação direta com seus ancestrais espirituais e seu povo. Não deve nada à imitação eurocentrada, nem com esta se compromete. Nossa representação não é calcada na reconstrução da vida cotidiana dos povos, mas para esta se dirige e edifica sua produção. Produção esta inicialmente pensada para atender aos rituais simbólicos sociais, de cerimônias fúnebres, batizados, casamentos e demais atos públicos. Considerando a forte relação destes povos com a natureza, conferindo aos seus um caráter holístico, não é demais pensar que esta conexão com água, terra, fogo e ar seja constante e plena, se utilizando destes na representação artística para organizar a expressão de comunhão com o mundo.

\section{REFERÊNCIAS}

AMÂNCIO, Íris da Costa. Entrançamentos discursivos na Literatura Angola do pósindependência (história, etnicidades e estética). Belo Horizonte: Nandyala, 2014. 
Teatro Angolano: dramaturgia, literatura e representações de etnicidades. Belo

Horizonte: Nandyala, 2014.

BARBOSA, Fernanda Júlia. Ancestralidade em Cena: candomblé e teatro na formação de uma encenadora. Dissertação (mestrado) - Universidade Federal da Bahia, Escola de Teatro. Salvador, 2016.

BONDÍA, Jorge Larrosa. Notas sobre a experiência e o saber de experiência. in Revista Brasileira da Educação. N¹9, Jan/Fev/Mar/Abr, P. 20-28. Rio de Janeiro: ANPED, 2002.

BRANDÃO, Junito de Souza. Mitologia Grega, vol. I, 22. Ed. - Petrópolis, RJ: Vozes, 2010.

BRUSTEIN, Robert. O Teatro de Protesto. Rio de Janeiro: Zahar Editores, 1967.

CAMPBELL, Joseph. O Poder do Mito. Tradução de Carlos Felipe Moisés. -São Paulo: Palas Athena, 1990.

CUNHA JUNIOR, Henrique. Ntu. In: Revista Espaço Acadêmico, V 09, No 108, p.81-92 Maio, 2010.

FÉRAL, Josette. Theatricality: the specificity of theatrical language. Borard of Regents, University of Wisconsin Press. SubStance 98/99, Vol. 31, nos. 2 \& 3, 2002. Disponível em: 〈htpp://www.jtor.org/stable/3685480> acesso em: 21/08/2017.

FERNANDES, Sílvia. Teatralidade e Performatividade na Cena Contemporânea. Revista Repertório, n 16, p.11-23. Salvador: UFBA/PPGAC, 2011.DIÉGUEZ, Ileana. Um Teatro sem Teatro: a teatralidade como campo expandido. Revista Sala Preta. Vol.14, n 1 , p. 125-129. São Paulo: USP / PPGAC, 2014.

LEHMANN, Hans-Thies. Teatro Pós-dramático. São Paulo: Cosac Naify, 2007.

LIMA, Evani Tavares. Capoeira Angola como Treinamento para o Ator. Dissertação (mestrado) - Universidade Federal da Bahia, Escola de Teatro. Salvador, 2002.

. Um olhar sobre o Teatro Negro do Teatro Experimental do Negro e do Bando de Teatro Olodum. Tese (doutorado) - Universidade Estadual de Campinas, Instituto de Artes. Campinas, SP, 2010.

Teatro Negro, existência por resistência: problemáticas de um teatro brasileiro. Revista Repertório, Salvador, $n^{\circ}$ 17, p.82-88, 2011.2.

KILOMBA, Grada. A Máscara. Cadernos de Literatura em Tradução / Faculdade de Filosofia, Letras e Ciências Humanas/USP. - n. 16, p.171-180. São Paulo : FFLCH/ USP, 1997

MACHADO, Marina Marcondes. A Criança é Perfomer. Revista Educação e Realidade. $\mathrm{N}^{\circ} 35$ (2), Mai/Ago, P. 115-117. Porto Alegre, 2010.

MACHADO, Vanda. Ilê Axé: vivências e invenção pedagógica - as crianças do Opô Afonjá. $2^{\mathrm{a}}$. ed - Salvador: Editora da Universidade Federal da Bahia, 2002.

- Exu: o senhor dos caminhos e das alegrias in Encontros Multidisciplinares de Cultura - ENECULT, VI, 2010, Salvador, Ba. Anais (on-line). Salvador: ENECULT, 2010. Disponível em: http://www.cult.ufba.br/wordpress/24929.pdf acesso em: 28/03/2018. 
MARTINS, Leda Maria. A Cena em Sombras. São Paulo: Perspectiva, 1995.

Edições, 1997.

Afrografias da Memória. São Paulo: Editora Perspectiva; Belo Horizonte: Mazza

MUNANGA, Kabengele. A Dimensão Estética na Arte Negro-Africana Tradicional, jun. 2006. Disponível em: http://www.macvirtual.usp.br/mac/arquivo/noticia/Kabengele/Kabengele.asp acesso em 01/02/2018.

PETIT, Sandra Haydée. Pretagogia: pertencimento, corpo-dança afroancestral e tradição oral contribuições do legado africano para a implementação da Lei 10.639/03. Fortaleza: EdUECE, 2015.

PINHEIRO, Giovanna Soalheiro. As Heranças Africanas na Narrativa de Mãe Beata de Yemonjá: mitologia, autoria e oralidade. UFMG, s/d.

OLIVEIRA, Eduardo David de. Filosofia da Ancestralidade: corpo e mito na filosofia da educação brasileira. Curitiba: Gráfica e Editora Popular, 2007.

RICOEUR, Paul. Tempo e Narrativa. Tomo I. São Paulo: Editora WMF Martins Fontes, 2010.

SARRAZAC, Jean-Pierre. A Invenção da Teatralidade. Tradução de Sílvia Fernandes da Silva Telesi. Revista Sala Preta. V.13, n.1, p.56-70. São Paulo: USP / PPGAC 2013.

SIMONI, Mariana. Atos performativos teóricos: sobre a performatividade no Teatro Contemporâneo. III Simpósio Nacional Discurso, Identidade e Sociedade. I Simpósio Internacional Discurso, Identidade e Sociedade: dilemas e desafios na contemporaneidade. São Paulo, 2002. Anais eletrônicos. São Paulo: UNICAMP, 2002 disponível em: http://www.iel.unicamp.br/sidis/anais Acesso em: 20/08/2017.

VANSINA, Jan. A Tradição Oral e sua Metodologia. In: ZERBO, J-KI. História Geral da África. São Paulo: Ed. Ática, 1982, p.152-180. 